\title{
The analysis of Web technologies for BIM model processing
}

\author{
Danylo Shkundalov, Tatjana Vilutiené* \\ Department of Construction Management and Real Estate, Vilnius Gediminas Technical University, Vilnius, Lithuania
}

\begin{abstract}
Web based BIM platforms are powerful tools for the architects and constructors therefore there exists big amount of such projects around the globe. Each of them has own advantages and disadvantages therefore it is important to understand which platform brings more benefits for the users in relation to the BIM model processing and project management. For this purposes Web based BIM systems need to be analysed and compared by their tools and opportunities. This paper is presenting the results of such comparison in condition of WebBIM platform development with the purpose of better understanding of the further development way.
\end{abstract}

Keywords: BIM, Project management, Web, GIS.

\section{Introduction}

Collaboration of the BIM and GIS in Web environments got their development in the last decade. This technology brings many benefits for constructors, architects, and managers. Exists a big amount of projects around the world that has been developed for this purpose. Each project brings different abilities and tools for BIM model processing and manipulation, therefore, it is important to analyse and compare the most outstanding Web solutions to estimate the best existing approaches for this technology. In this article, no front-end or back-end technological solutions are analysed, as there is no difference for the user with which libraries solutions are made. WebBIM platform developed by the author and presented in scientific articles needs to be compared as well to determine the way of future development. The presented projects are compared by the opportunities they bring for the civil engineers and architects, implemented functionality with related tools and technologies that are used. Web-based solutions can not bring the same level of the functionality as their installation-based analogy, however the main purpose is to understand the average level of the abilities that this kind of platforms brings into construction solutions around the globe and what they can propose for the constructors and architects to extend the opportunities in condition of project planning and management.

\section{Literature analysis}

The integration of BIM and GIS can offer substantial benefits to manage the planning process during the preconstruction stage. BIM provides geometry, spatial relationships, and quantities of building components, GIS can use them to support a wide range of spatial analysis used in an early phase of the procurement process, and BIM can visualize the results of the GIS analyses in a 3D virtual world (Irizarry \& Karan, 2012). Karan and Irizarry (2015) done a good overview of the BIM model conversion scientific approaches the main aim of which is to process a BIM model geometric and attributive information in way that is more native. Some of the scientific articles are highlighting the standardization issues and proposing the solutions for it, as there is no accepted standards for the BIM and GIS collaboration (Noor et al., 2018). However, one of the main topic related to BIM and GIS collaboration in the Web environment is a lack of technological solutions for achieving the full tack of needs.

The main issues can be described in the next way: BIM model cannot be processed inside the Web environment in a native way, therefore, models need to be converted; BIM models can not completely produce model of the real objects in the high accuracy; 3D mesh models of the objects created by the photogrammetry cannot be properly processed in the BIM model inside the Web environment. This problem has been described in many scientific articles (Ma \& Ren, 2017; Niu, Pan, \& Zhao, 2015; Rechichi, Mandelli, Achille, \& Fassi, 2016; Liu et al, 2017; Pauwels, Zhang, \& Lee, 2017; Zhong, Gan, Luo, \& Xing, 2018; Zhu, Wright, J. Wang, \& X. Wang, 2018; Wong, Ge, \& He, 2018; Zhou, Wang, Guo, \& Gao, 2019). The interoperability between different information systems still remain challenging. Moreover, Web

\footnotetext{
${ }^{*}$ Corresponding author. E-mail: tatjana.vilutiene@vgtu.lt
}

(C) 2019 Authors. Published by VGTU Press. This is an open-access article distributed under the terms of the Creative Commons Attribution (http://creativecommons.org/licenses/by/4.0/) License, which permits unrestricted use, distribution, and reproduction in any medium, provided the original author and source are credited. 
solutions need to be able to process dynamic data and wide data to present proper GIS data layouts in relation to BIM model representation. These issues are strictly related to the BIM and GIS collaboration inside the Web environment, therefore, it is important to analyze the opportunities that can be provided by the most powerful Web-based solutions developed for such purposes.

\section{Results of Case studies analysis}

From a big amount of the Web solutions, the following projects were selected: BIMData, Autodesk (a360) BIM 360, ESRI Web AppBuilder, Helsinki 3D + and Virtual Singapore (Singapore 3D). All of these platforms provide the opportunity to visualize BIM models in the Web environment and manipulate with related to the model data. The main criteria for the comparison are opportunities to manipulate with the model and objects presented in this model and manipulate the files that present the model. The results of this comparison are presented in Table 1.

Table 1. Comparison of Web solutions for BIM model processing

\begin{tabular}{|l|c|c|c|c|c|c|c|}
\hline \multicolumn{1}{|c|}{ Platform } & $\begin{array}{c}\text { Native } \\
\text { file type }\end{array}$ & $\begin{array}{c}\text { Model } \\
\text { manipulation }\end{array}$ & $\begin{array}{c}\text { Objects } \\
\text { manipulation }\end{array}$ & $\begin{array}{c}\text { GIS } \\
\text { data }\end{array}$ & $\begin{array}{c}\text { GIS } \\
\text { analysis }^{1}\end{array}$ & $\begin{array}{c}\text { Inspectorate } \\
\text { tools }\end{array}$ & $\begin{array}{c}\text { Project } \\
\text { management }^{2}\end{array}$ \\
\hline $\begin{array}{l}\text { BIMData (BIMData. } \\
\text { Documentation, 2019) }\end{array}$ & - & + & + & + & - & + & $+/+$ \\
\hline $\begin{array}{l}\text { Autodesk BIM 360 (Autodesk } \\
\text { Knowledge Network. BIM 360, } \\
\text { 2019) }\end{array}$ & + & + & + & + & - & + & $+/+$ \\
\hline $\begin{array}{l}\text { ESRI Web AppBuilder (Web } \\
\text { AppBuilder for ArcGIS, 2019; } \\
\text { Developer documentation for } \\
\text { the ArcGIS platform, 2019) }\end{array}$ & + & + & - & + & $+/+$ & + & $+/+$ \\
\hline $\begin{array}{l}\text { Helsinki 3D+ (Helsinki's 3D } \\
\text { city models, 2019) }\end{array}$ & - & - & - & + & $+/-$ & + & $+/-$ \\
\hline $\begin{array}{l}\text { Virtual Singapore (Virtual } \\
\text { Singapore, 2019) }\end{array}$ & - & - & - & + & $+/+$ & + & + \\
\hline $\begin{array}{l}\text { WebBIM (WebBIM. } \\
\text { Visualisation, manipulation, } \\
\text { sharing, 2019) }\end{array}$ & - & + & + & + & $-/+$ & + \\
\hline
\end{tabular}

${ }^{1}$ presents two parameters where first - opportunity to present the results of the GIS analysis done outside of the Web solution; second performs GIS analysis inside the Web solution environment.

${ }^{2}$ presents two parameters where first - upload BIM model by the Web solution; second manages project files by the solution tools.

All of the platforms have the opportunity to process IFC file formats however just BIM 360 and Web AppBuilder can process proprietary file formats such as .rvt. The proprietary file formats cannot be presented by default within Web technologies because of this such files need to be converted to the JSON structured representation and placed inside the WebGL scene. All future manipulations need to be done with this representation. It is important because in case file format cannot be processed natively then while the conversion process inaccuracy appears. The important feature for the architecture is manipulation with the model - move and rotate. Most of the platforms allow such manipulation, however, less number of them allows manipulating with the objects inside the model.

The integration of GIS data is important because it brings many benefits such as real-world representation model, sensors implementation, real-time updating, etc. GIS integration can be done in all of the platforms as all of them are Web based, however, just ESRI Web AppBuilder and Singapore project can visualize and perform some of the GIS analysis with the BIM model. GIS analysis can extend the opportunities of the BIM environment due to the big amount of GIS surveys. Helsinki 3D+ can perform analysis by using 3D models based on the B-Rep model and WebBIM platform at the moment has just one GIS analysis that is shadow casting (Shkundalov, 2017), therefore, this project cannot be considered as analysis-ready.

All of the platforms allow to inspectorate a model and the most powerful solution for these purposes is presented in Autodesk BIM 360 platform as it brings not just tools to examine the objects but timelines of the changes as well. Moreover, BIM 360 and BIMData projects allow changing the attributive information of the objects. The best tools for the project management are presented in BIM 360 (Figure 1a) and BIMData (Figure 1b) because they provide the opportunity not just to upload and delete files but show changes in real-time. Moreover, these solutions bring close team collaboration not just in document management but in the BIM model commenting as well. WebBIM solution just allows loading and deleting models and not presents real-time changes.

The results can be performed by two parameters: GIS implementation and BIM implementation, and based on these two points the comparison results should be reviewed. The analysis of the selected Web solutions shows that the most powerful projects are Autodesk BIM 360 and ESRI Web AppBuilder. Autodesk solution brings powerful tools for 
model manipulation as well as objects manipulation with which user has the opportunity to manage each facility and whole model, make plans and even explode the model. Moreover, BIM 360 brings an outstanding project management system with a big amount of opportunities such as real-time project update, changes share, timelines, notifications and much more. On the other hand, no GIS analysis are implemented. ESRI web AppBuilder doesn't provide the same range of opportunities to manipulate with BIM model and its objects, however, this solution contains the biggest amount of GIS analysis and tools for their performance.
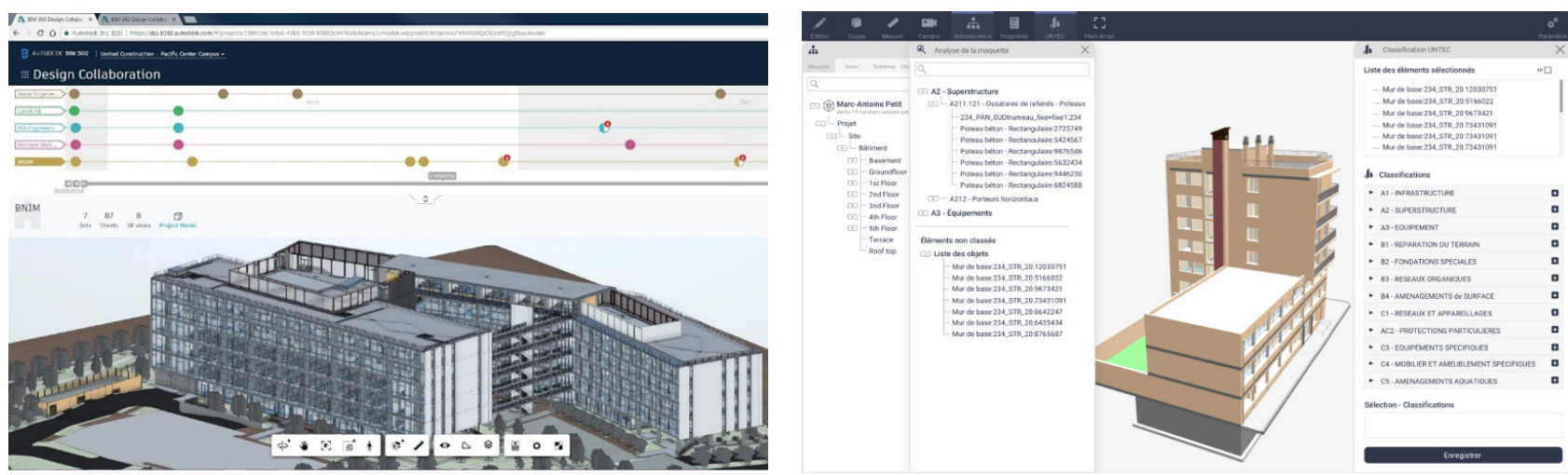

Figure 1. The tools for the project management: a) Autodesk BIM 360 project management; b) BIMData project management

Most of the manipulations with the BIM model need to be done in the ArcGIS Pro and after that exported to the Web AppBuilder therefore from the civil engineering point of view this solution is not so good to be used however from the GIS point of view this platform should be considered as the best one to work with in case analysis with BIM model need to be done. BIMData is the middle point between mentioned solutions as it has a good project management system, allows manipulating with the model as well as connect GIS data, but no GIS analysis are implemented. Opposite to BIMData Virtual Singapore shows really good GIS abilities and has opportunity to visualize BIM model, however, this solution does not provide tools to work with the BIM model apart from inspectorate tools, the project can be managed but not so good as in other solutions, therefore, cannot be used in most BIM cases.

WebBIM platform brings tools to manipulate with the BIM model as well as model's objects but not as good as Autodesk solution; it has a GIS environment that is presented as a real mesh model and one analysis but not as much as ESRI or Virtual Singapore solutions. Models can be uploaded and deleted but no project management system is presented at the moment. In the proprietary solutions such as Autodesk BIM 360 the BIM model conversion process is implemented on the server-side that brings easy BIM model implementation for the users and in WebBIM solution the BIM model need to be converted inside the proprietary program installed on the PC within third-party addons that brings inconvenience in BIM model implementation process. This happens because the proprietary file types such as rvt are crypted and cannot be processed outside of the related software or without a cryptography algorithm. Moreover, WebGL technology does not provide BIM model logic that is implemented inside the proprietary programs: no object relations or rules are presented therefore they need to be developed in each Web-based solution.

\section{Conclusions}

It is expected that such strong companies as Autodesk and ESRI are leaders in own fields but they are focusing just in their fields and implementation of the second field is like an addition to their own. On the other hand, smaller projects such as BIMData and WebBIM platforms show the idea of close collaboration between BIM and GIS environments that leads to a bigger amount of opportunities in total.

The best way of developing the solutions that are designed for the collaboration between BIM and GIS is to focus on the collaboration but not a single environment. Such a platform needs to have good tools for model manipulation as well as model's objects manipulation that is highly important for the civil engineers and architects; strong project management system that allows sharing changes in real-time and GIS module where need to be presented different GIS analysis.

Sadly, but it is doubtful that proprietary file formats will be opened for processing by third-party companies soon. The way of WebBIM platform development should focus on the project management system first, after that model manipulation tools should be expanded and in the end, more GIS analysis should be implemented. 


\section{References}

Autodesk Knowledge Network. BIM 360. (2019). Retrieved from https://knowledge.autodesk.com/support/bim-360

BIMData. Documentation. (2019). Retrieved from https://developers.bimdata.io/

Developer documentation for the ArcGIS platform. (2019). Retrieved from https://developers.arcgis.com/documentation/

Helsinki's 3D city models. (2019). Retrieved from www.hel.fi/helsinki/en/administration/information/general/3d/3d

Irizarry, J., \& Karan, E. P. (2012). Optimizing location of tower cranes on construction sites through GIS and BIM integration. Journal of information technology in construction (ITcon), 17(23), 351-366.

Karan, E. P., \& Irizarry, J. (2015). Extending BIM interoperability to preconstruction operations using geospatial analyses and semantic web services. Automation in Construction, 53, 1-12. https://doi.org/10.1016/j.autcon.2015.02.012

Liu, X., Wang, X., Wright, G., Cheng, J. C., Li, X., \& Liu, R. (2017). A state-of-the-art review on the integration of Building Information Modeling (BIM) and Geographic Information System (GIS). ISPRS International Journal of Geo-Information, 6(2), 53. https://doi.org/10.3390/ijgi6020053

Ma, Z., \& Ren, Y. (2017). Integrated application of BIM and GIS: an overview. Procedia Engineering, 196, $1072-1079$. https://doi.org/10.1016/j.proeng.2017.08.064

Niu, S., Pan, W., \& Zhao, Y. (2015). A BIM-GIS integrated web-based visualization system for low energy building design. Procedia Engineering, 121, 2184-2192. https://doi.org/10.1016/j.proeng.2015.09.091

Noor, S., Shah, L., Adil, M., Gohar, N., Saman, G. E., Jamil, S., \& Qayum, F. (2018). Modeling and representation of built cultural heritage data using semantic web technologies and building information model. Computational and Mathematical Organization Theory, 25(3), 247-270. https://doi.org/10.1007/s10588-018-09285-y

Pauwels, P., Zhang, S., \& Lee, Y. C. (2017). Semantic web technologies in AEC industry: A literature overview. Automation in Construction, 73, 145-165. https://doi.org/10.1016/j.autcon.2016.10.003

Rechichi, F., Mandelli, A., Achille, C., \& Fassi, F. (2016). Sharing high-resolution models and information on web: the web module of BIM3DSG system. In 23rd International Archives of the Photogrammetry, Remote Sensing and Spatial Information Sciences Congress (pp. 703-710). Prague, Czech Republic. https://doi.org/10.5194/isprsarchives-XLI-B5-703-2016

Shkundalov, D. (2017). Development of visualization and manipulation methods for BIM and digital city models using Web graphic library. In $20^{\text {th }}$ Conference for Junior Researchers ,, Science - Future of Lithuania. 24 March 2017. Vilnius, Lithuania.

Virtual Singapore. (2019). National Research Foundation. Retrieved from http:/www.nrf.gov.sg/programmes/virtual-singapore

Web AppBuilder for ArcGIS. (2019). Retrieved from https://developers.arcgis.com/web-appbuilder/

WebBIM. Visualisation, manipulation, sharing. (2019). Retrieved from http://www.webbim.do.am/

Wong, J. K. W., Ge, J., \& He, S. X. (2018). Digitisation in facilities management: A literature review and future research directions. Automation in Construction, 92, 312-326. https://doi.org/10.1016/j.autcon.2018.04.006

Zhong, B., Gan, C., Luo, H., \& Xing, X. (2018). Ontology-based framework for building environmental monitoring and compliance checking under BIM environment. Building and Environment, 141, 127-142. https://doi.org/10.1016/j.buildenv.2018.05.046

Zhou, X., Wang, J., Guo, M., \& Gao, Z. (2019). Cross-platform online visualization system for open BIM based on WebGL. Multimedia Tools and Applications, 78(20), 28575-28590. https://doi.org/10.1007/s11042-018-5820-0

Zhu, J., Wright, G., Wang, J., \& Wang, X. (2018). A critical review of the integration of geographic information system and building information modelling at the data level. ISPRS International Journal of Geo-Information, 7(2), 66. https://doi.org/10.3390/ijgi7020066 